\title{
The Nutrition Transition in Developing Asia: Dietary Change, Drivers and Health Impacts
}

\author{
Matthew Kelly
}

\begin{abstract}
This chapter reviews the likely consequences of dietary change for human health and wellbeing in Asia where a transition is occurring from diets dominated by low fat, high fibre foods to increased consumption of processed and packaged convenience foods. These foods are higher in fats, sugars and salt and are linked to increased rates of diet-related non-communicable disease. The chapter traces between-country differences and considers the drivers of dietary change including economic growth and rising incomes, the effects of urbanization and changing family size, the industrialization of food systems and the liberalization of world trade. While levels of malnutrition have declined throughout the region, rates of obesity ad overweight have increased raising challenging questions for nutrition policy planners.
\end{abstract}

Keywords Nutrition transition - Dietary change - Population health - Obesity • Asia

\section{What Is the Nutrition Transition?}

Throughout human history there have been profound shifts in population diets and these shifts inevitably have impacted on nutritional status and population health. In recent decades a particularly rapid process of change has been observed, first in high income countries but now also in low and middle income settings (Popkin 2002a, b; Drenowski and Popkin 1997; Popkin et al. 2012; Kearney 2010). Diets dominated by starchy, low variety, low fat, high fiber foods are being replaced by consumption of processed foods higher in fats, sugars and salt, and accompanied by rises in diet-related non-communicable disease. These changes in population diet

M. Kelly (ه)

Department of Global Health, Research School of Population Health,

ANU College of Medicine, Biology and Environment,

The Australian National University, Acton, ACT 2601, Australia

e-mail: matthew.kelly@anu.edu.au

(C) The Author(s) 2016

P. Jackson et al. (eds.), Eating, Drinking: Surviving,

SpringerBriefs in Global Understanding, DOI 10.1007/978-3-319-42468-2_9 
are referred to by Popkin as "Nutrition Transitions" (Popkin 2002a, b, 2006). Asia which is home to half of the world's population and which is the fastest growing region economically is particularly susceptible to the negative aspects of this nutrition transition and will be the focus of the remainder of this chapter.

\section{Dietary Change in Asia}

Across countries and regions within Asia there is substantial variation in the manifestation of the nutrition transition. However, there are several key changes that have been observed in most settings:

(1) The most common change in the region is a dramatic increase in the proportion of dietary energy derived from oils and fats, mainly oilseed based, replacing complex carbohydrate sources. World production of edible oilseeds has almost tripled in the last half century. The demand for this production increase has been most important in East and Southeast Asia (Drenowski and Popkin 1997). For example, China increased annual vegetable oil consumption per capita from $1 \mathrm{~kg}$ in 1963 to $11 \mathrm{~kg}$ in 2003, and in middle income Asia overall per capita annual consumption rose from $1.5 \mathrm{~kg}$ to nearly $6 \mathrm{~kg}$ in a similar time period. The change in animal fat consumption has been more modest, rising from around $0.2 \mathrm{~kg} /$ person/year to around $1.5 \mathrm{~kg}$ (Kearney 2010).

(2) The proportion of energy derived from caloric sweeteners in Asian diets has also been increasing. In the last half of the 20th Century the middle income countries of Asia increased their annual per capita refined sugar consumption from 12 to $31 \mathrm{~kg}$, the highest income groups increased their consumption from 4 to $36 \mathrm{~kg}$ and even in the poorest Asian countries consumption increased from 3 to $9 \mathrm{~kg}$ (Popkin et al. 2001).

(3) The predominant rice based diets of Asia are changing with wheat consumption taking its place. This is not a universal process however with increasing incomes in the poorest Asian countries leading to increased rice consumption while middle income transitional countries move away from rice. For example in China rice consumption increased rapidly in the 1960s and 1970s from 172 grams/capita/day in 1963 to 260 in 1983 before falling again to 213 in 2003. In the same 40 years wheat consumption increased from 71 grams/person/day to 167 (Kearney 2010).

(4) Along with wheat, consumption of other temperate zone products has also been increasing in Asia. Imports of temperate zone fruit, vegetable, dairy and other animal products has increased by 13 times in the last 4 decades and is also driving dietary change and homogenisation to a more western style diet. Potato consumption has been particularly interesting with Asia's share of world output increasing from 8 to $28 \%$ since the 1960s (Pingali 2007). 
(5) Consumption of meat has also been increasing as part of a nutrition transition in Asia. The largest change here has been seen in pork and poultry consumption. In China for example, from 1990 to 2014 pork consumption more than doubled from 15 to $31 \mathrm{~kg} /$ capita/year and poultry from 2 to $11.5 \mathrm{~kg}$ (Meat consumption 2016).

(6) Possibly the most important dietary change, and one which incorporates the 5 changes described above, is the increase in consumption of processed, packaged and convenience foods. These foods generally high in fat, salt or sugar, are scientifically designed to be hyper palatable. In China consumption of processed foods increased from $20 \mathrm{~kg} /$ capita annually in 1999 to over 80 in 2012, and in Thailand from 60 to $110 \mathrm{~kg}$. Substantial increases in just one decade. Between country differences in the composition of processed food consumption is noteworthy. In Thailand and the Philippines soft drink consumption is particularly high and approaches high income country levels, in Malaysia and Indonesia processed high fat foods were most problematic. In higher income Asian countries such as Japan consumption of processed foods has plateaued since the 1990s, at a much higher level than in middle and low income Asia, but is growing fastest in the upper-middle income countries such as Thailand and China (Baker and Friel 2014).

\section{Drivers of the Asian Nutrition Transition}

Asia, with some exceptions, has enjoyed substantial economic growth in recent decades and this is reflected in rising incomes and increased consumer purchasing power. Many studies have observed the markers of the nutrition transition in decreased complex carbohydrate consumption and increased fat, salt, sugar and processed food consumption corresponding with rising national incomes (Drenowski and Popkin 1997). This situation however is beginning to change. For reasons which will be discussed below nutrition transitions are now being seen at lower and lower levels of income (Popkin et al. 2012). Equally as important as income growth is the rapid pace of urbanization in Asia. By 2020 half of the world's population will live in urban centers and half of these urbanites will live in Asia. Urban settings provide both access to novel "modern" foods and cultural and lifestyle change. An important aspect of urban life is increasingly time poor consumers, particularly as more women enter the work force. Time poor consumers increase demand for convenience processed foods. As well, smaller families are more common in urban Asia inducing changes in eating patterns with large family meals requiring home cooking becoming less common (Pingali 2007).

The major supply factor enabling the nutrition transition is the industrialization and globalization of food systems (Hawkes 2006; Hawkes et al. 2012). The post-World War II period saw the expansion of industrialized agriculture and trade in agricultural products across much of the world. Over subsequent decades this 
trade increasingly came to be in more processed food products and transnational corporations began to control each stage of the food system (Clapp 2013). Integral to this process has been the rapid expansion of bilateral, multilateral, and regional free trade agreements which have opened markets to food imports and importantly also to foreign investment in food industries (Hawkes 2005). This has included food retail sectors and Asia has seen supermarkets expand rapidly since the 1990s again increasing consumer access to globalized foods and in particular making processed energy dense foods more easily affordable and available (Kearney 2010; Kelly et al. 2014).

Overall we can observe that greater global market integration, measured by percentage of Gross Domestic Product (GDP) provided by foreign direct investment, correlates strongly with exposure to unhealthy food products (Stuckler et al. 2012). Trade liberalization has induced prices for animal fats, dairy products, sugars, and oils to fall worldwide. Thus the processed, energy dense foods which drove the nutrition transition in western countries become more available but also cheaper (Hawkes 2006). As well, globalized food chains have the largest comparative advantage in supplying processed foods high in sugar, salt, and oil which are cheaper to produce and transport and have longer shelf lives than do raw unprocessed foods (Popkin 2006; Hawkes 2008; Chopra et al. 2002).

\section{Health Effects of the Nutrition Transition}

The nutrition transition does not have to have negative outcomes. Rising incomes and food availability can and do have substantially positive outcomes on population health. In fact famine and malnutrition have receded in many developing countries with a global average rise of $400 \mathrm{kcal}$ per person per day in the last 3 decades (Kearney 2010). However while malnutrition has been receding in Asia overall, rates of overweight and obesity are rising rapidly, particularly in Southeast Asia (Popkin 2006; Chopra et al. 2002). For example from 1980 to 2008 prevalence of adult overweight and obesity combined increased from 12 to $39 \%$ in Thailand, from 15 to nearly $50 \%$ in Malaysia and from 5 to around $25 \%$ in Indonesia (Stevens et al. 2012). As well the burden of diet-related disease including diabetes, cardiovascular disease and diet-related cancers is also rising. Non-communicable diseases such as these already account for more than half of deaths in Southeast Asia and have steadily increased over the last two decades replacing infectious diseases and maternal and child mortality (World Health Organisation 2011).

The health effects of the nutrition transition can be more severe in developing countries where economic change has happened more rapidly than in European countries. People born into an environment of low nutrition, who later in life experience a surplus of energy dense food are more likely to develop heart disease, diabetes, and hypertension. At a very young age, or even before birth, bodies adapt to the nutritional situation they find themselves in meaning when more energy becomes available the body is maladapted to cope with it (Godfrey and Barker 
2001). This has already been found to have an influence on public health in the Asia-Pacific region where low birth weights and childhood malnutrition were highly prevalent just 20-30 years ago (Binns et al. 2001). This problem may be exacerbated even further in Asian populations who have been observed to have higher body fat ratios and higher disease risk at a lower body mass index than European populations (WHO expert consultation 2004).

\section{Conclusions}

Dietary change in Asia over recent decades has had many positive effects. The late twentieth century globalized food system has increased food availability overall and thus improved one aspect of food security, the production or supply of sufficient food to meet the aggregate energy requirements of the population. However, sufficient caloric availability does not equate to optimal nutrition, particularly, where the globalized food trade makes energy dense processed foods cheaper than fresh healthy foods (Pinstrup-Andersen 2009). The main target of food policies in the context discussed in this paper should be to achieve economic growth and food security while avoiding the negative impacts of the nutrition transition. One important consideration in fast developing settings like much of Asia is that countries will not move through transitional stages sequentially as predicted by nutrition transition theory. Changes in the affordability and availability of problematic processed foods are occurring at lower and lower levels of income. It will therefore be particularly important in transitional settings in Asia to remain aware of the common dual-burden of under and over nutrition in the same country and sometimes even the same household. This requires approaches which maintain dietary energy availability while ensuring it comes from health promoting sources.

How this is to be achieved is still unclear and there are very few models of success in modifying dietary change and related health impacts, particularly in developing Asia. However there is a growing awareness that effective food policy must address the food system in an integrated ecological manner (Carlisle and Hanlon 2014; Lang 2009; Lang et al. 2009). This includes addressing upstream influences on consumption and nutrition including the relative price and availability of energy dense, processed foods. Also important is addressing the effect of agricultural policies on population diets, for example by encouraging a move away from edible oil production towards greater fruit and vegetable production thus 
improving local availability of health promoting foods as is currently been trialed in China. Perhaps most effective may be support for the retention of traditional Asian diets, both to decrease the impact of the nutrition transition, but also to support local food producers. There is some evidence from Southeast Asia indicating that making traditional diets more convenient and affordable may, particularly among younger generations, encourage resistance to western, transitional diets (Seubsman et al. 2009). This approach has also enjoyed some success in South Korea which has maintained healthier eating patterns than most other Asian countries and has also enjoyed lower levels of underweight and obesity than other countries at comparable stages of economic development. These achievements have been in part linked to intensive government publicity and education campaigns combined with subsidies and support for local food product production and consumption (Lee et al. 2002). Such integrated food policies may be the most promising avenue for nutrition policy planners in Asia.

\section{References}

Baker, P., \& Friel, S. (2014). Processed foods and the nutrition transition: Evidence from Asia. Obesity Reviews, 15(7), 564-577.

Binns, C. W., Lee, M., \& Scott, J. A. (2001). The fetal origins of disease hypothesis: Public health implications for the Asia-Pacific region. Asia Pacific Journal of Public Health, 13, 68-73.

Carlisle, S., \& Hanlon, P. (2014). Connecting food, well-being and environmental sustainability: Towards an integrative public health nutrition. Critical Public Health, 24(4), 405-417.

Chopra, M., Galbraith, S., \& Darnton-Hill, I. (2002). A global response to a global problem: The epidemic of overnutrition. Bulletin of the World Health Organisation, 80(12), 952-958.

Clapp, J. (2013). Food. Hoboken: Wiley.

Drenowski, A., \& Popkin, B. M. (1997). The nutrition transition: New trends in the global diet. Nutrition Reviews, 55(2), 31-43.

Godfrey, K. M., \& Barker, D. J. P. (2001). Fetal programming and adult health. Public Health Nutrition, 4(2b), 611-624.

Hawkes, C. (2005). The role of foreign direct investment in the nutrition transition. Public Health Nutrition, 8(04), 357-365.

Hawkes, C. (2006). Uneven dietary development: Linking the policies and processes of globalization with the nutrition transition, obesity and diet-related chronic diseases. Globalisation and Health, 2(1), 4.

Hawkes, C. (2008). Dietary implications of supermarket development: A global perspective. Development Policy Review, 26(6), 657-692.

Hawkes, C., Friel, S., Lobstein, T., \& Lang, T. (2012). Linking agricultural policies with obesity and noncommunicable diseases: A new perspective for a globalising world. Food Policy, 37(3), 343-353.

Kearney, J. (2010). Food consumption trends and drivers. Philosophical Transactions of the Royal Society B: Biological Sciences, 365(1554), 2793-2807.

Kelly, M., Seubsman, S. A., Banwell, C., Dixon, J. \& Sleigh, A. (2014). Thailand's food retail transition: Supermarket and fresh market effects on diet quality and health. British Food Journal, 116(7), 1180-1193.

Lang, T. (2009). Reshaping the food system for ecological public health. Journal of Hunger and Environmental Nutrition, 4(3), 315-335. 
Lang, T., Barling, D., \& Caraher, M. (2009). Food policy: Integrating health, environment and society. Oxford: Oxford University Press.

Lee, M.-J., Popkin, B. M., \& Kim, S. (2002). The unique aspects of the nutrition transition in South Korea: The retention of healthful elements in their traditional diet. Public Health Nutrition, 5(1a), 197-203.

Meat consumption [Internet]. (2016). [cited April 27, 2016].

Pingali, P. (2007). Westernization of Asian diets and the transformation of food systems: Implications for research and policy. Food Policy, 32(3), 281-298.

Pinstrup-Andersen, P. (2009). Food security: Definition and measurement. Food Security, 1, 5-7.

Popkin, B. M. (2002a). What is unique about the experience in lower and middle income less-industrialised countries compared with the very-high income industrialised countries: The shift in stages of the nutrition transition in the developing world differs from past experiences. Public Health Nutrition, 5(1A), 205-214.

Popkin, B. M. (2002b). An overview of the nutrition transition and its health implications: The Bellagio meeting. Public Health Nutrition, 5(1A), 93-103.

Popkin, B. M. (2006). Global nutrition dynamics: The world is shifting rapidly toward a diet linked with noncommunicable diseases. American Journal of Clinical Nutrition, 84(2), 289-298.

Popkin, B. M., Adair, L. S., \& Ng, S. W. (2012). Global nutrition transition and the pandemic of obesity in developing countries. Nutrition Reviews, 70(1), 3-21.

Popkin, B. M., Horton, S. H. \& Kim, S. (2001). The nutrition transition and prevention of diet-related diseases in Asia and the Pacific. Food and Nutrition Bulletin, 22(4 supplement).

Seubsman, S., Kelly, M., Yuthapornpinit, P., \& Sleigh, A. (2009). Cultural resistance to fast food consumption? A study of youth in North Eastern Thailand. International Journal of Consumer Studies, 33, 669-675.

Stevens, G. A., Singh, G. M., Lu, Y., Danaei, G., Lin, J. K., Finucane, M. M. et al. (2012). National, regional, and global trends in adult overweight and obesity prevalences. Population Health Metrics, 10(22).

Stuckler, D., McKee, M., Ebrahim, S., \& Basu, S. (2012). Manufacturing epidemics: The role of global producers in increased consumption of unhealthy commodities including processed foods, alcohol, and tobacco. PLoS Med, 9(6), e1001235.

WHO Expert Consultation. (2004). Appropriate body-mass index for Asian populations and its implications for policy and intervention strategies. Lancet, 363, 157-163.

World Health Organisation. (2011). Non-communicable diseases in the South East Asia region: Situation and response. New Delhi: WHO, Regional Office for Southeast Asia.

Open Access This chapter is distributed under the terms of the Creative Commons Attribution 4.0 International License (http://creativecommons.org/licenses/by/4.0/), which permits use, duplication, adaptation, distribution and reproduction in any medium or format, as long as you give appropriate credit to the original author(s) and the source, provide a link to the Creative Commons license and any changes made are indicated.

The images or other third party material in this chapter are included in the work's Creative Commons license, unless indicated otherwise in the credit line; if such material is not included in the work's Creative Commons license and the respective action is not permitted by statutory regulation, users will need to obtain permission from the license holder to duplicate, adapt or reproduce the material.

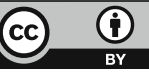




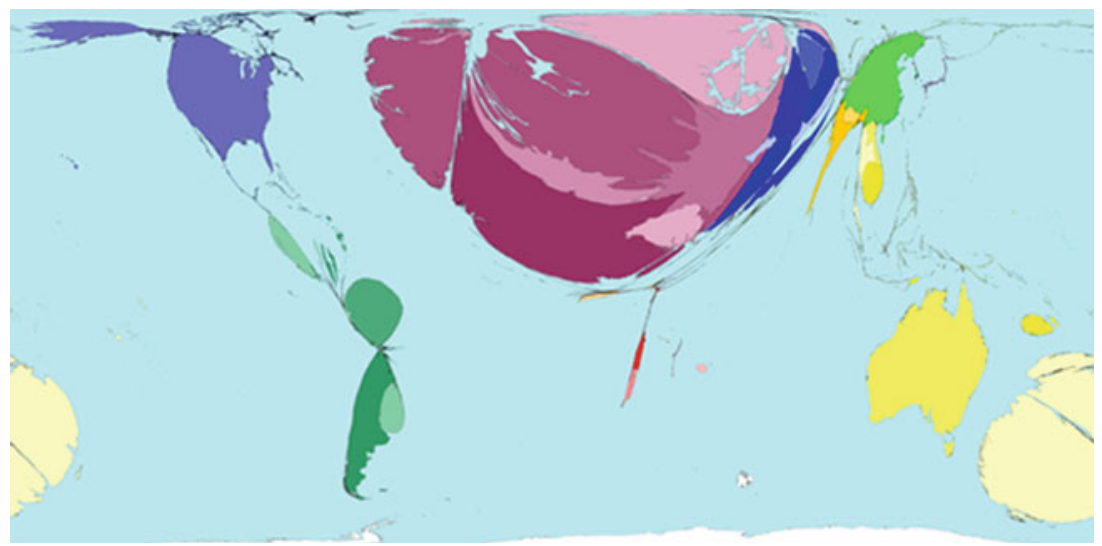

Dairy exports. Dairy products include milk, butter, cheese and eggs. As with many trade maps, Europe is large and Africa is very small on this map. Territory size shows the proportion of worldwide net exports of dairy produce (in US\$) that come from there. Net exports are exports minus imports. When imports are larger than exports the territory is not shown. Source www.worldmapper.org. Published with kind permission of (C) Copyright Benjamin D. Hennig (Worldmapper Project)

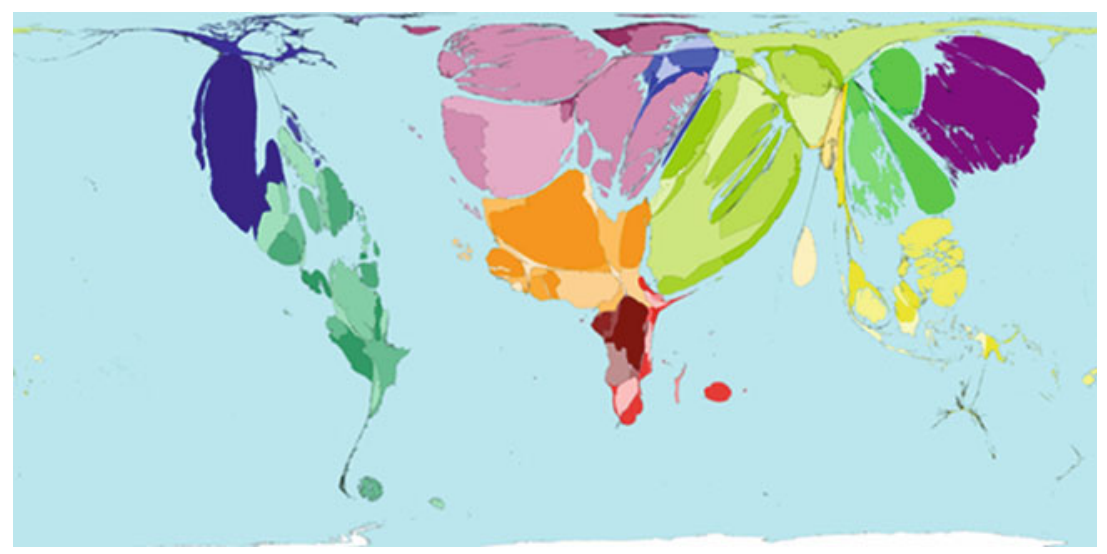

Dairy imports. Dairy imports exceed exports in every region except for Asia Pacific, Eastern Europe and Western Europe. The Middle East, Northern Africa and Japan have the largest regional net imports. Territory size shows the proportion of worldwide net imports of dairy produce (in US\$) that are received there. Net imports are imports minus exports. When exports are larger than imports the territory is not shown. Source www.worldmapper.org. Published with kind permission of $(C$ Copyright Benjamin D. Hennig (Worldmapper Project) 